\title{
mau \\ Onion Germplasm Possesses Lower Early Season Thrips Numbers
}

\author{
Seyed Shahabeddin Nourbakhsh (1) and Christopher S. Cramer *
}

Department of Plant and Environmental Sciences, New Mexico State University, P.O. Box 30003, MSC 3Q, Las Cruces, NM 88003, USA; nshahab@nmsu.edu

* Correspondence: cscramer@nmsu.edu

Citation: Shahabeddin Nourbakhsh,

S.; Cramer, C.S. Onion Germplasm

Possesses Lower Early Season Thrips

Numbers. Horticulturae 2022, 8, 123.

https://doi.org/10.3390/horticulturae 8020123

Academic Editor: Luigi De Bellis

Received: 21 December 2021

Accepted: 27 January 2022

Published: 29 January 2022

Publisher's Note: MDPI stays neutral with regard to jurisdictional claims in published maps and institutional affiliations.

Copyright: (c) 2022 by the authors. Licensee MDPI, Basel, Switzerland. This article is an open access article distributed under the terms and conditions of the Creative Commons Attribution (CC BY) license (https:// creativecommons.org/licenses/by/ $4.0 /)$.

\begin{abstract}
Onion is one of the most valuable vegetable crops in the US. Onion thrips were identified as one of the main threats to the US onion industry. An integrated approach, including host plant tolerance, is required. For this study, four New Mexico State University breeding lines, along with two thrips-attractive cultivars, were evaluated for their attractiveness to thrips. In addition, this study observed thrips population dynamics throughout the growing season and the relationship between onion plant size and thrips attractiveness. The experiment was designed as a randomized complete block design with three blocks, each containing four replications. Thrips-infested bulbs were used to ensure the presence of thrips and thrips-attractive plants were used to ensure equal thrips distribution throughout the field. Ten plants were randomly selected from each plot and thrips and leaf numbers were counted multiple times through the growing season. Plants of NMSU breeding lines were observed to have fewer thrips, be more tolerant to thrips pressure and produce more leaves and larger bulbs than thrips-attractive entries. Early in the growing season, leaf number was not a determining factor in thrips population dynamics. The larger bulb weights of the breeding lines allowed them to maintain their market value. A delay in thrips population buildup in plants of the breeding lines may result in the critical threshold for spraying for thrips being reached later in these lines. This would potentially allow for fewer pesticide applications by growers, increasing growers' profits and ensuring a more environmentally friendly approach to plant production.
\end{abstract}

Keywords: Allium cepa; integrated pest management; Iris yellow spot virus; pest tolerance; Thrips tabaci

\section{Introduction}

Onion is one of the most valuable vegetable crops in the US with an annual farm-gate value of more than USD 1 billion [1]. Onion thrips have been identified as a threat to the US onion industry and are quite complex and very difficult to manage [2]. Onion thrips (Thrips tabaci Lindeman) are cosmopolitan and polyphagous insects that routinely infest and damage onion crops and are the most important insect pest of onion in the US [3]. Thrips feeding reduces onion leaf photosynthetic area, removes the contents of mesophyll cells in onion leaves, causes severe leaf damage and creates silvery patches and curled leaves. This results in substantial reductions ( 30 to $50 \%$ ) in bulb yields and in seed yields, due to the girdling and lodging of seed scapes [4-6]. Viruliferous onion thrips, containing the Iris yellow spot virus (IYSV) in their system, live an average of 3.6 days longer than nonviruliferous thrips [7]. This prolonged life span is positively correlated with fecundity, allowing viruliferous thrips to inflict more damage, infect more plants and exacerbate IYSV epidemics [7]. If hot and dry climatic conditions that are favorable to thrips persist, Iris yellow spot (IYS) disease can destroy entire onion fields [8]. These climatic conditions shorten thrips generation times and increase thrips buildup, subsequently increasing the damage that is caused by them and the virus [8].

Frequent applications of organophosphates, carbamates and pyrethroids have been the primary management method for onion thrips. These insecticides are not very effective because onion thrips have developed resistance to some commonly used insecticides [4]. Complete spray coverage is difficult to achieve because thrips eggs are protected by leaf 
tissues, prepupae and pupae reside in the soil and larvae and some adults feed in the inner spaces between leaves, often outside the reach of insecticide applications [4,9-11]. Chemical control methods become ineffective at temperatures over $30^{\circ} \mathrm{C}$, since some insecticides have more rapid chemical breakdown at higher temperatures, which reduces their activity and effectiveness [12].

Past research indicates that certain leaf colors, such as blue, are more attractive to thrips [13]. It has also been demonstrated previously that thrips populations and feeding damage vary depending upon the amount and type of epicuticular wax on leaves [14]. Onions with waxy leaves are very susceptible to thrips feeding and suffer severe damage, since they allow thrips to adhere to the plant and incite damage [5,14,15]. Research has found that onions with waxy leaves suffer more thrips damage compared to onions with semi-glossy and glossy leaves, since their leaves accumulate only intermediate or sparse amounts of epicuticular waxes and have lighter green colors that result in slower thrips population growth and reduced egg hatching [8,14,16-19]. Lower wax phenotypes can be conditioned by a single recessive locus $(g l)$, such as the single recessive locus $\left(g l^{\text {wp }}\right)$ found in the glossy phenotype White Persian, which has been mapped to chromosome 8 and been shown to interact with a region of chromosome 1 that acts to increase waxy progeny numbers [20-23]. Relative to other epicuticular waxes, the amount of hentriacontanone-16 wax may also influence the total amount of leaf wax [24]. The cultivar Odorless Greenleaf, however, which has glossy leaves, has experienced less thrips feeding damage while having no hentriacontanone-16 wax [25]. Additionally, the angle of the leaf also seems to affect thrips feeding damage, as thrips mostly reside in the axil of the basal parts of the leaf, with tighter angles restricting thrips access [26].

Control of thrips requires an integrated approach that includes chemical control of thrips, cultural practices and genetic resistance/tolerance. An economic and environmentally friendly solution for controlling thrips can be provided by host plant resistance [2] Using even partially thrips-tolerant onion cultivars can greatly impact the costs and returns to onion growers, since reduced insecticide applications could increase profits from $\$ 641.10$ to $\$ 1013.63$ per hectare when compared to most current management practices and yields [27]. Over the last decade, the NMSU onion breeding program has evaluated and screened germplasm for reduced thrips numbers, greater plant vigor and reduced IYS disease symptom expression [20,28-31]. Several plant introduction accessions exhibited a reduction in IYS symptom severity and thrips numbers [8]. After selection for reduced IYS symptom development, plants of second-generation selections NMSU 12-257, NMSU 12-258, NMSU 12-260, NMSU 12-261, NMSU 12-774, NMSU 12-279, NMSU 12-289 and NMSU 12-325 exhibited fewer thrips when compared to plants of a thrips-attractive cultivar, Rumba [2]. In the same study, plants of NMSU 12-279, NMSU 12-255, NMSU 12-298, NMSU 12-289 and NMSU 12-258 exhibited fewer thrips when compared to plants of their first-generation entries, indicating selection progress even though selection was not for fewer thrips [2]. Progress for reducing thrips numbers per plant was observed in several breeding lines, including NMSU 12-236, NMSU 12-243, NMSU 12-335, NMSU 12-337 and NMSU 12-796, when compared to their respective original population and Rumba, showing the possibility of further progress through additional indirect selection cycles [32]. Different levels of thrips resistance have been observed in onion germplasm across the world, including VI038512 and AVON 1067 being identified as resistant and VI038552 being identified as highly resistant in Tanzania; Vale Ouro IPA 11, BRS Alfa São Francisco, Franciscana IPA 10 and Sirius F1 being identified as resistant in Brazilian semi-arid regions and NIKSP-86 being identified as highly resistant and T-821 and Ceylon being identified as resistant in the Punjabi region of India [33-35]. A delay in the buildup of thrips could explain some of the differences observed.

As selection progress for reduced IYS symptom expression has been observed with NMSU breeding lines, a reduction in thrips numbers per plant has also been observed [36-39]. To determine the mechanisms involved in reduced thrips numbers, NMSU breeding lines exhibiting reduced thrips numbers were characterized in greater detail. As with previous 
studies [32], we hypothesized that early in the growing season, NMSU breeding lines are less attractive to thrips, and therefore less populated by thrips, than thrips-attractive entries. Moreover, we hypothesized that there is a strong positive correlation between plant size and thrips numbers, as previously observed between thrips population size and plant height [40]. We hypothesized that NMSU breeding lines have fewer thrips and suffer less thrips damage mainly because of different foliar characteristics, such as leaf color and wax amounts, which are caused by genetic differences. In addition, we hypothesized that plants that have fewer thrips will produce larger-sized bulbs than plants that have more thrips, since it has been demonstrated that a positive correlation exists between plant height and bulb yield, while a negative correlation exists between thrips population size and yield [40].

\section{Materials and Methods}

\subsection{Plant Material and Sowing}

Since 2009, individual onion bulbs that exhibited less thrips feeding damage have been selected from different NMSU onion breeding lines. These lines were selected based on historical knowledge of reduced thrips numbers from a previous study on IYS [8,31]. They have been grown and evaluated for IYS disease and thrips numbers in Oregon state, as well [38]. These lines originated from crosses made by other researchers between lines or cultivars which belong to Grano and Sweet Spanish onion types [32,39]. Five entries, including four second-generation selections (prefix NMSU 12-), and two commercial cultivars Rumba and Stockton Early Yellow, which were evaluated in 2013 and 2014, were chosen for this study [8,31]. These selections had different ancestries; NMSU 12-236 originated from NMSU 07-52-1, NMSU 12-236 originated from NMSU 07-52-1, NMSU 12-238 and NMSU 12-243 originated from NMSU 07-53-1 and NMSU 12-337 originated from NMSU 07-54-1 [31]. These selections were assessed for waxiness in previous studies, where NMSU 12-236, NMSU 12-238 and NMSU 12-243 were visually classified as semi-glossy, plants of NMSU 12-337 were classified as glossy, 'Rumba' was classified as waxy and 'Stockton Early Yellow' was classified as having light wax [31,39]. These lines and cultivars were also visually rated for leaf color in previous studies, where NMSU 12-337, NMSU 12-238, NMSU 12-243 and NMSU 12-236 were considered dark green, while plants of the thrips-attractive entries had more bluish colors than the breeding lines, with 'Rumba' being considered blue and 'Stockton Early Yellow' blue green, which is due to genetic and wax compositions differences [31,39]. These lines were originally selected because of visible reduced/delayed IYS symptom expression and disease severity, which may be explained by genetic differences, different maturity dates, inherent tolerance to stress and fewer thrips numbers, which is why they were selected for further breeding and analyses [2,32]. For the second and the third years of the study, Rumba was replaced with another thrips-attractive, commercial cultivar, Stockton Early Yellow, since the seeds of Rumba were no longer produced.

Seeds of these lines were sown in the Fabian Garcia Science Center (FGSC) greenhouses in January 2019, 2020 and 2021, and in March of each respective year, plants were transplanted to the field. Seeds for all entries were sown in 4-inch-deep black plastic flats filled with Metro-Mix 360 (Sun Gro Horticulture, Bellevue, WA, USA). Miracle-Gro (15-30-15; N-P-K; Scotts Miracle-Gro Company, Marysville, OH) fertilizer was applied to enhance seedling growth. Seedlings at the four-to-five leaf stage were transplanted to a field at the FGSC in the first and second years of the study and to the Leyendecker Plant Science Research Center (LPSRC) in the third.

Some modifications were made in the first year of the study, since there were not enough seedlings for certain plots of 'Rumba' and NMSU 12-337 at the initial date of transplanting, so additional seeds were sown in the greenhouse and seedlings were transplanted to the field at a later date in a portion of the third replication. In the third year of the study, some plants of all entries were transplanted to the field at a later date, as some initially transplanted seedlings did not survive. As a result, they contained plants that were a different size than plants that were transplanted earlier in other plots. 


\subsection{Field Design}

The fields at the FGSC for the first and second years of the study and at the LPSRC for the third in Las Cruces, NM were arranged as a randomized complete block design with three blocks, each containing four replications. Plots were $3.3 \mathrm{~m}$ in length and consisted of 2 planted, equally spaced rows on a planted bed with plants spaced $7-8 \mathrm{~cm}$ apart within the row. A drip irrigation system equipped with control valves for each bed was used. One-meter spacing between the beds was ensured for irrigation and equipment movement. Drip irrigation tape (Irritec, Fresno, CA, USA) with $20 \mathrm{~cm}$ between emitters was placed at the center of a bed at a depth of $10 \mathrm{~cm}$. Plants were irrigated as needed [41]. In the first year of the study, Glendale loam and Brazito very fine sandy loam with a thick surface were the soil types. Harkey clay loam was the soil type for the second year of the study and Brazito very fine sandy loam with a thick surface was the soil type for the third year of the study [42]. For the first year of the study, the second and third replications were set apart from the first replication in the same field, whereas in the second and third years of the study, all three replications were adjacent.

Plants were grown using standard cultural practices recommended for onion production in southern New Mexico [41]. However, no insecticide was applied to plants in order to preserve the thrips population. The field layout used for this study has been used in previous years and has been quite effective in spreading onion thrips and IYS throughout the field and was used for this study with some modifications [8,29-31,36,37]. Thrips-infested bulbs from the previous year's study had been placed on the first and last bed of the study and at the front and back borders of the study in October of the previous year to ensure that onion thrips, and therefore IYSV, were in the field and to provide a continuous supply of leaf tissue for onion thrips to feed upon. Right next to beds of thrips-infested bulbs, a locally adapted cultivar, NuMex Freedom, which was known to be attractive to thrips, was sown at the same time to ensure that thrips were spread throughout the field. As a result, there were six beds for research plots between two beds of 'NuMex Freedom' plants. For the second year of the study, however, there were 5 beds between two beds of 'NuMex Freedom' plants. The field was designed in such a way that onion thrips would live on the infested bulbs until scape formation and then would move on to the plants of 'NuMex Freedom', and, once these plants matured, they would move to the test plants.

\subsection{Data Collection}

Ten plants were randomly selected and identified with plastic labels from each plot. These ten plants were revisited multiple times through the growing season for data collection. The number of adult and juvenile thrips were counted in a nondestructive manner by separating the leaves and examining the axil from each of those ten plants from each plot at five separate times $(8,10,12,14$ and 16 weeks after transplant (WAT)) during the crop's growth to ensure that enough thrips existed. However, in the third year of the study, data collection began at 6 WAT, and no data were collected at 12 WAT, due to inaccessibility of the field after rainfall. In addition, leaf numbers (living leaves) of the same ten plants were counted on the same observation dates, and bulb weight of these plants was measured (in grams) at harvest (considered mature when 80 percent of the tops were down), using a scale. In addition, thrips number per leaf was calculated by dividing individual plants' thrips numbers by the plants' leaf numbers.

\subsection{Data Analysis}

The mean of each character, including total, juvenile and adult thrips numbers, leaf numbers and average bulb weight for each entry, were calculated using the PROC MEANS and PROC MIXED commands, on a per plot basis, in SAS (SAS 9.0; SAS Institute Inc., Cary, NC, USA). Standard errors of the means were also calculated. In the second and third years of the study, several plots had to be excluded from the analyses since several plants were planted at later dates, had different maturity dates, died before a complete season's worth of data could be collected and/or exhibited improper growth and smaller 
size. In order to determine which plots should be excluded, the mean bulb weight of the four replications within a block was calculated for each entry. In addition, the standard deviations of the means were also calculated. If an individual plant's bulb weight was more than one standard deviation lower than its mean of the four replications for that entry, the plant would be considered an outlier. Thereafter, plots with four or less plants were considered missing and excluded from the analyses.

In the PROC MIXED analysis, entries were considered fixed effects while blocks and replications were considered random effects. This analysis was used to determine if there were trait differences among entries. In addition, the PDIFF statement was used to determine if there were trait differences between the thrips-attractive entries and individual NMSU breeding lines. PROC CORR was used to determine correlations between traits on a per individual plant basis. Multiple comparison tests were not performed, and the breeding lines were compared to the thrips-attractive cultivars.

\section{Results and Discussion}

\subsection{Onion Thrips Numbers among Entries and Their Population Dynamics}

There were differences in thrips numbers between NMSU breeding lines and thripsattractive entries, with plants of NMSU 12-236, NMSU 12-238, NSMU 12-243 and NSMU 12-337 exhibiting fewer onion thrips per leaf than plants of the thrips-attractive entries, 'Rumba' or 'Stockton Early Yellow' (Table 1). In 2019, 'Rumba' exhibited about seven thrips per leaf at 8 WAT, whereas NMSU breeding lines exhibited about 1.4 to 1.8 thrips per leaf (Table 1). In 2020, 'Stockton Early Yellow' exhibited about 7.4 thrips per leaf, while NMSU breeding lines had 1.8 to 2.8 thrips per leaf at 8 WAT. While the numbers were lower in 2021, more thrips were still observed on plants of 'Stockton Early Yellow' at 8 WAT than plants of the NMSU breeding lines (Table 1). Similar results have been observed before with respect to difference in thrips numbers [2,32]. Previously, this difference in thrips numbers was attributed to differences in epicuticular leaf wax amounts [14,32]. In terms of leaf wax phenotypes, plants of NMSU 12-236, NSMU 12-238 and NMSU 12-243 were visually classified in previous studies as semi-glossy and plants of NMSU 12-337 were classified as glossy, while 'Rumba' was classified as waxy and 'Stockton Early Yellow' as having light wax [31]. NMSU breeding lines also were greener in leaf color, with NMSU 12-337, NMSU 12-238, NMSU 12-243 and NMSU 12-236 considered dark green, while plants of the thrips-attractive entries had more bluish colors than the breeding lines, with 'Rumba' being considered blue and 'Stockton Early Yellow' blue green, which is due to genetic differences and different wax compositions $[31,39]$. Since onion thrips are more attracted to leaves with higher wax contents and bluish colors, the differences observed in thrips numbers are most likely due to differences in foliage attributes [5,13-15].

Table 1. Total number of thrips per leaf for five onion entries counted five times at two weeks apart during the 2019, 2020 and 2021 growing seasons while plants were grown at the Fabian Garcia Science Center and Leyendecker Plant Science Research Center, Las Cruces, NM ${ }^{\mathrm{z}}$.

\begin{tabular}{lccccc}
\hline \multicolumn{7}{c}{ Observation Date } \\
\hline Entry & $\mathbf{1}$ & $\mathbf{2}$ & $\mathbf{3}$ & $\mathbf{4}$ & $\mathbf{5}$ \\
\hline \multicolumn{7}{c}{$1.4^{\mathrm{x}} \pm 0.4^{\mathrm{w}}$} & $3.4 \pm 0.5$ & $4.8 \pm 0.7$ & $4.4 \pm 0.6$ & $0.9 \pm 0.2$ \\
\hline NMSU 12-236 & $1.7 \pm 0.4$ & $3.4 \pm 0.5$ & $5.9 \pm 0.7$ & $2.8 \pm 0.6$ & $0.5 \pm 0.2$ \\
\hline NMSU 12-238 & $1.4 \pm 0.4$ & $2.3 \pm 0.5$ & $4.1 \pm 0.7$ & $3.1 \pm 0.6$ & $0.5 \pm 0.2$ \\
\hline NMSU 12-243 & $1.8 \pm 0.4$ & $2.6 \pm 0.6$ & $3.4 \pm 0.7$ & $4.5 \pm 0.7$ & $2.3 \pm 0.2$ \\
\hline NMSU 12-337 & $7.0 \pm 0.5$ & $8.5 \pm 0.6$ & $10.5 \pm 0.8$ & $5.7 \pm 0.7$ & $1.2 \pm 0.3$ \\
\hline Rumba & $* * *$ & $* * *$ & $* *$ & $* *$ & $* *$ \\
\hline
\end{tabular}


Table 1. Cont.

\begin{tabular}{lccccc}
\hline \multicolumn{5}{c}{ Observation Date $\mathbf{y}$} \\
\hline Entry & $\mathbf{1}$ & $\mathbf{2}$ & $\mathbf{3}$ & $\mathbf{4}$ & $\mathbf{5}$ \\
\hline NMSU 12-236 & $1.8 \pm 0.3$ & $4.5 \pm 0.7$ & $6.4 \pm 0.6$ & $4.2 \pm 0.7$ & $0.6 \pm 0.1$ \\
\hline NMSU 12-238 & $2.8 \pm 0.3$ & $5.7 \pm 0.7$ & $3.8 \pm 0.7$ & $0.6 \pm 0.7$ & $0.1 \pm 0.1$ \\
\hline NMSU 12-243 & $1.9 \pm 0.3$ & $4.5 \pm 0.7$ & $4.9 \pm 0.6$ & $2.3 \pm 0.7$ & $0.2 \pm 0.1$ \\
\hline NMSU 12-337 & $2.1 \pm 0.3$ & $4.2 \pm 0.7$ & $6.7 \pm 0.6$ & $3.4 \pm 0.7$ & $0.6 \pm 0.1$ \\
\hline Stockton Early Yellow & $7.4 \pm 0.3$ & $8.9 \pm 0.7$ & $4.8 \pm 0.6$ & $1.7 \pm 0.7$ & $0.3 \pm 0.1$ \\
\hline & $* * *$ & $* * *$ & $* *$ & $* * *$ & $*$ \\
\hline NMSU 12-236 & $0.2 \pm 0.3$ & $0.3 \pm 0.3$ & $1.1 \pm 0.4$ & - & $1.7 \pm 0.3$ \\
\hline NMSU 12-238 & $0.8 \pm 0.3$ & $1.3 \pm 0.3$ & $1.8 \pm 0.4$ & - & $1.0 \pm 0.3$ \\
\hline NMSU 12-243 & $1.9 \pm 0.3$ & $1.4 \pm 0.4$ & $1.3 \pm 0.4$ & - & $1.0 \pm 0.3$ \\
\hline NMSU 12-337 & $0.7 \pm 0.3$ & $1.3 \pm 0.3$ & $1.7 \pm 0.3$ & - & $1.7 \pm 0.3$ \\
\hline Stockton Early Yellow & $2.1 \pm 0.5$ & $4.6 \pm 0.4$ & $3.6 \pm 0.4$ & - & $1.1 \pm 0.3$ \\
\hline & $* * *$ & $* * *$ & $* * *$ & & NS
\end{tabular}

${ }^{z}$ Seeds of each entry were sown in a greenhouse in January. In March, plants were transplanted to the field, where thrips-infested bulbs from the previous year's study had been placed in October of the previous year to ensure that onion thrips were in the field. The field was arranged as an RCBD with three blocks and four replications in each block. Conventional vegetable cultural practices and drip irrigation were utilized for all trials. ${ }^{y}$ The observation dates were 8,10,12,14 and 16 weeks after transplanting for the first year of the study, 8, 10, 12, 15 and 17 after transplanting for the second and 6,8,10 and 14 weeks after transplanting for the third year of the study. No data were collected at the fourth observation date in the third year of the study. ${ }^{x}$ Thrips were counted by separating the leaves and examining the axil. Ten plants per plot were chosen randomly to undergo thrips count and the same ten plants were revisited at different time periods and thrips loads were counted. Number of thrips per leaf was measured by dividing individual plants' thrips numbers by the plants' leaf numbers. Plot means were calculated for thrips number per leaf at each observation date using the PROC MEANS statement in SAS Studio. In addition, the PROC MIXED statement with fixed effects was used to calculate means, and random effects were not considered. Entry means highlighted in italics represent that the entry mean was different from the thrips-attractive entry. ${ }^{\mathrm{w}}$ Standard error of the mean. NS, ${ }^{*}, * *, * * *$ Nonsignificant at $p=0.05$, significant at $p=0.05$, significant at $p=0.01$ and significant at $p=0.001$, respectively. Test was conducted at $\alpha=0.05$.

Onion thrips dynamics varied depending on the time within the growing season and entries, but the total number of thrips per leaf was usually at its maximum at the third observation date in each year (Table 1). Fewer thrips were usually observed in the first two observation dates depending upon the year (Table 1), as observed also in past research [2,32]. With the number of thrips per leaf increasing on plants of the NMSU breeding lines and decreasing for plants of the thrips-attractive entries, plants of the NMSU lines did not exhibit fewer thrips per leaf than plants of the thrips-attractive entries after the third observation date (Table 1). One likely explanation for the difference is that even though the majority of the thrips population on plants was comprised of juvenile thrips (Tables S1 and S2) and the numbers of total and juvenile thrips were strongly positively correlated (mostly with a correlation coefficient greater than 0.95 at $p<0.001$ ), adult thrips were most likely responsible for the differences observed in thrips numbers among entries and through time (Table 2). Early in the growing season, plants of 'Rumba' and 'Stockton Early Yellow' had a greater number of adult thrips when compared with plants of the NMSU breeding lines (Table 2). Due to wax differences among entries, adult thrips would first move onto attractive plants, feed off them and lay eggs on them, as they seem to be better sources of food for their offspring, resulting in greater numbers of larvae. From that point on, it took about 20 days in total for a new generation to develop, depending on temperature [43]. As the new generation of adult thrips sought new food sources, they found plants of the thrips-attractive entries damaged, fed-upon and less attractive. At that point, adult thrips looked towards nearby breeding lines that had not been fed 
upon as severely and moved onto them. This reasoning explains why the numbers of total and juvenile thrips per plant increased later in the season (Tables S1 and S2) and why thrips numbers did not decrease as rapidly on NMSU breeding lines as they did on thrips-attractive entries after the third observation date (Table 1). An earlier observation date may have shown differences in adult thrips numbers among entries, as the number of juvenile thrips is high and they comprise most of the thrips populations (Tables S1 and S2).

Table 2. Number of leaves and adult thrips per leaf for five onion entries counted two weeks apart during the 2019, 2020 and 2021 growing seasons while plants were grown at the Fabian Garcia Science Center and Leyendecker Plant Science Research Center, Las Cruces, NM ${ }^{\mathrm{z}}$.

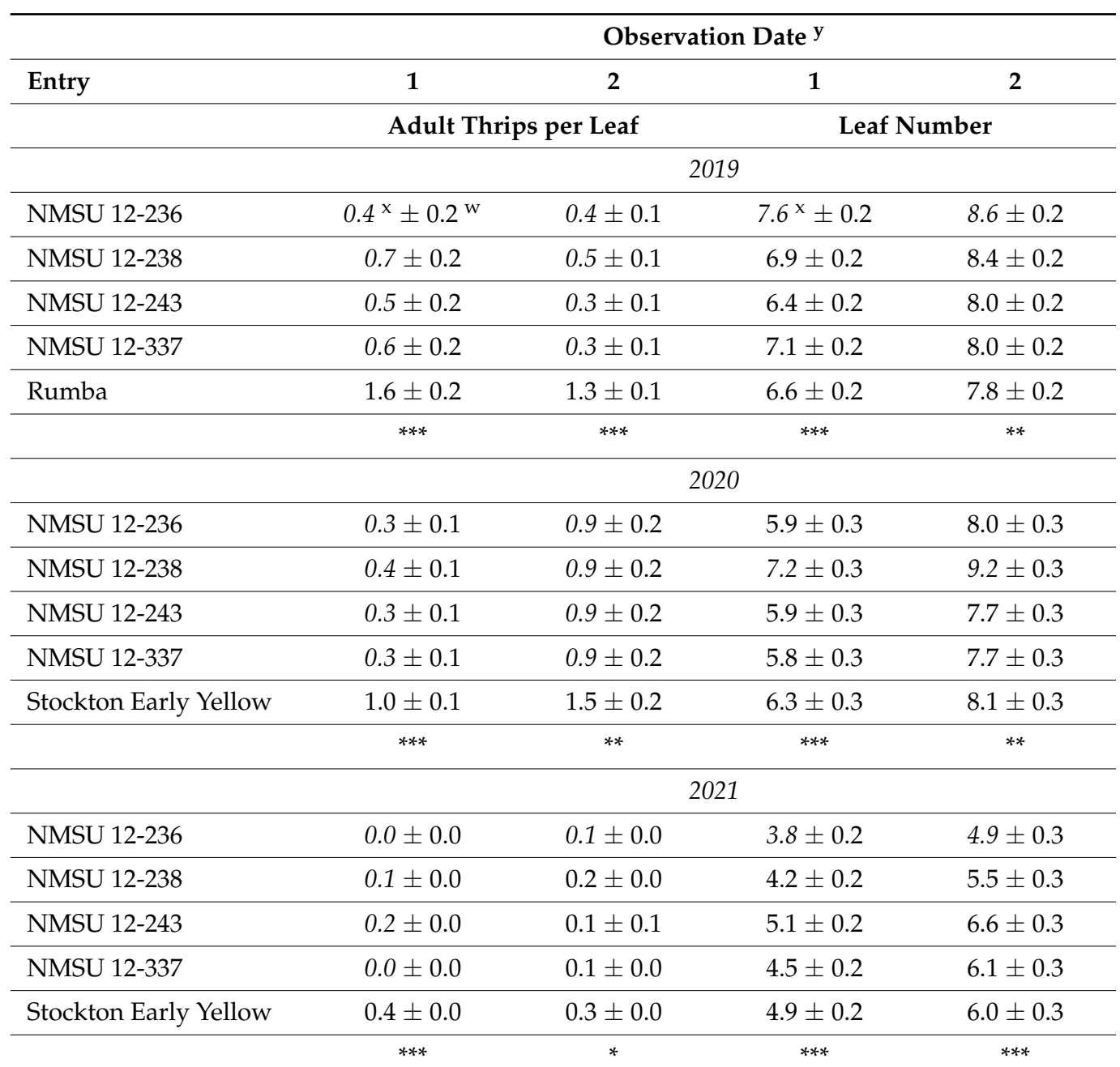

zeeds of the germplasm were sown in a greenhouse in January. In March, plants were transplanted to the field, where thrips-infested bulbs from the previous year's study had been placed in October to ensure that onion thrips were in the field. The field was arranged as an RCBD with three blocks and four replications in each block. Conventional vegetable cultural practices and drip irrigation were utilized for all trials. $\mathrm{y}$ The observation dates were 8 and 10 weeks after transplanting for the first and second years of the study and 6 and 8 weeks after transplanting for the third year of the study. ${ }^{x}$ All the living leaves on the plant were counted and adult thrips were counted by separating the leaves and examining the axil. Ten plants per plot were chosen randomly to undergo leaf number and adult thrips count, and the same ten plants were revisited at different time periods and thrips loads and leaf numbers were counted. Number of adult thrips per leaf was measured by dividing individual plants' adult thrips numbers by the plants' leaf numbers. Plot means were calculated for leaf numbers and thrips numbers per plant at each observation date using the PROC MEANS statement in SAS Studio. In addition, the PROC MIXED statement with fixed effects was used to calculate means, and random effects were not considered. Entry means highlighted in italics represent that the entry mean was different from the thrips-attractive entry. ${ }^{\mathrm{w}}$ Standard error of the mean. ${ }^{\mathrm{N}},{ }^{*}, * * * * *$ Nonsignificant at $p=0.05$, significant at $p=0.05$, significant at $p=0.01$ and significant at $p=0.001$, respectively. Test was conducted at $\alpha=0.05$. 
Onion thrips thrive in hot and dry climatic conditions [8]. In the third year of the study, however, lower maximum air temperature during the growing season and higher total precipitation were observed (Figures S1 and S2), which may have caused the differences in buildup of the thrips population (Table 1). In the third year of the study, data collection began at 6 weeks after transplanting, whereas in the first and second years, it began at 8 weeks after transplanting. Even though these conditions had affected thrips numbers and plant size, the same dynamics were observed in 2021, further confirming that foliar characteristics mainly drive thrips population dynamics and buildup.

\subsection{Leaf Number and Bulb Weight}

Leaf number and its change through time do not account for the observed thrips population dynamics. Since plants of the NMSU breeding lines were similar or greater in leaf number when compared to plants of the thrips-attractive entries early in the season (Table 2), leaf number may not have been a determining factor for the higher thrips populations observed on the plants of the thrips-attractive entries, further confirming that foliar characteristics, such as leaf waxiness and color, are the main causes for the higher number of thrips observed on these entries. Later in the season, some breeding lines exhibited greater leaf numbers, possibly explaining the greater numbers of thrips observed when plants with attractive foliar characteristics were no longer as easily available for feeding (Table 1), as similarly observed in past research, where thrips numbers and plant height were positively correlated [39]. Thrips and leaf numbers were positively correlated, especially in the beginning of the growing season, and more strongly positively correlated in the thrips-attractive entries in the first and second years of the study. On the first observation date of all three years of the study, thrips and leaf numbers were positively correlated in the thrips-attractive entries, with correlation coefficients between 0.57 and 0.63 (Figure S3). NMSU breeding lines also exhibited a positive correlation between 0.34 and 0.58 on the first observation date of all three years of the study (Figure S3). These results indicate that plants of the NMSU breeding lines were able to produce similar or greater numbers of leaves in comparison with the thrips-attractive entries, even when under maximum thrips pressure.

In the first and second years, plants of the NMSU breeding lines exhibited greater average bulb weights than plants of the thrips-attractive entries, with NMSU breeding lines having average bulb weights between about $174.0 \mathrm{~g}$ and $223.9 \mathrm{~g}$, whereas thrips-attractive entries had average bulb weights between about $95.4 \mathrm{~g}$ and $102.9 \mathrm{~g}$ (Table 3 ). In the third year, only plants of NMSU 12-243 with a bulb weight of $160.3 \mathrm{~g}$ and 12-337 with a bulb weight of $170.2 \mathrm{~g}$ were greater than plants of 'Stockton Early Yellow' (82.8 g) (Table 3). Given the greater average bulb weight of the NMSU breeding lines in the presence of high thrips pressure, it seems that these lines were more tolerant to thrips feeding damage and that their growth and development was not affected by thrips pressure. Inherent genetic differences may also have contributed to these results, as the NMSU breeding lines produce larger plants than thrips-attractive entries and are more tolerant to stress [8]. Additionally, the delay in buildup of thrips populations may have allowed plants of the NMSU lines to be established and suffer less thrips damage at the more susceptible early stages of growth [43].

\subsection{Implications and Future Studies}

The differences observed in leaf and thrips numbers in this study indicate that plants of the NMSU breeding lines were more tolerant to thrips pressure and produced more leaves, and therefore larger bulbs, than thrips-attractive entries. These results indicate the potential for achieving thrips-tolerant cultivars. While the average bulb weights of the thrips-attractive entries placed them in the full-sized bulb US market class (less than $123 \mathrm{~g}$ ), the NMSU breeding lines produced mostly jumbo class bulb weight averages (between 206 and $460 \mathrm{~g}$ ) and medium class bulb weight averages (between 123 and $206 \mathrm{~g}$ ) [44,45]. The larger bulb weights of the NMSU breeding lines under thrips pressure allow them to avoid dropping in market classes and therefore maintain their market value, as onion prices tend 
to change as bulbs go from one market class to another [27,44]. Moreover, the delay in thrips population buildup between plants of the NMSU breeding lines and thrips-attractive entries may mean that the critical threshold for spraying for thrips, which is one to five thrips per leaf depending on the insecticide [46], would be reached later in these lines, potentially allowing for fewer pesticide applications by growers, increasing growers' profits from $\$ 641.10$ to $\$ 1013.63$ per hectare by also preventing a reduction in market class [27] and ensuring a more environmentally friendly approach to plant protection and production [2]. For future studies, we recommend examining the performance of NMSU breeding lines in the presence of maximum thrips pressure and in the absence of thrips-attractive cultivars.

Table 3. Average bulb weight for five onion entries measured five times at two weeks apart during the 2019, 2020 and 2021 growing seasons while plants were grown at the Fabian Garcia Science Center and Leyendecker Plant Science Research Center, Las Cruces, $\mathrm{NM}^{\mathrm{z}}$.

\begin{tabular}{lccc}
\hline & \multicolumn{3}{c}{ Year } \\
\hline Entry & $\mathbf{2 0 1 9}$ & $\mathbf{2 0 2 0}$ & $\mathbf{2 0 2 1}$ \\
\hline \multicolumn{3}{l}{ Average Bulb Weight $(g)$} \\
\hline NMSU 12-236 & $186.1^{y} \pm 11.2^{\mathrm{x}}$ & $174.0 \pm 12.0$ & $60.7 \pm 11.3$ \\
\hline NMSU 12-238 & $207.1 \pm 11.2$ & $234.2 \pm 12.0$ & $101.7 \pm 11.3$ \\
\hline NMSU 12-243 & $198.8 \pm 11.2$ & $201.8 \pm 12.0$ & $160.3 \pm 11.9$ \\
\hline ThSH 12-337 $^{*}$ & $223.9 \pm 11.2$ & $194.3 \pm 12.0$ & $170.2 \pm 10.8$ \\
\hline & $102.9 \pm 11.2$ & $95.4 \pm 12.0$ & $82.8 \pm 11.9$ \\
\hline
\end{tabular}

${ }_{\mathrm{z}}$ A plot was considered mature when 80 percent of the tops were down and it was harvested at that time. ${ }^{\mathrm{y}}$ PROC MIXED was used to determine differences between entries using plot means. In the model, entries were considered fixed. Entry means highlighted in italics represent that the entry mean was different from the thrips-attractive entry. ${ }^{x}$ Standard error of the mean. ${ }^{\mathrm{w}}$ In the first year of the study, Rumba was the thrips-attractive entry, and in the second and third years, Stockton Early Yellow was. ${ }^{* * *}$ Significant at $p=0.001$. Test was conducted at $\alpha=0.05$.

Supplementary Materials: The following supporting information can be downloaded at: https:// www.mdpi.com/article/10.3390/horticulturae8020123/s1, Figure S1. Maximum air temperatures from 1 May to 31 August for 2019, 2020, and 2021(New Mexico Climate Center in Fabian Garcia Science Center in 2019 and Leyendecker Plant Science Research Center in 2020 and 2021). Figure S2. Total precipitation from 1 May to 31 August of each year (New Mexico Climate Center in Fabian Garcia Science Center in 2019 and Leyendecker Plant Science Research Center in 2020 and 2021). Figure S3. Correlations, on a per plant basis, between total thrips per plant and leaf number through the growing season for entries in A) 2019, B) 2020, and C) 2021, at $p<0.001$ significance level. Table S1. Total number of thrips per plant for five onion entries counted at five times two weeks apart during the 2019, 2020 and 2021 growing seasons when plants were grown at the Fabian Garcia Science Center and Leyendecker Plant Science Research Center, Las Cruces, $\mathrm{NM}^{\mathrm{Z}}$. Table S2. Number of juvenile thrips per plant for five onion entries counted at five times two weeks apart during the 2019, 2020 and 2021 growing seasons when plants were grown at the Fabian Garcia Science Center and Leyendecker Plant Science Research Center, Las Cruces, $\mathrm{NM}^{\mathrm{Z}}$.

Author Contributions: S.S.N. collected the data, performed the analysis and wrote the manuscript; C.S.C. collected data and wrote the manuscript. All authors have read and agreed to the published version of the manuscript.

Funding: This research was funded by the USDA-NIFA Specialty Crop Research Initiative, grant number: 2018-03407, and the New Mexico Agricultural Experiment Station.

Institutional Review Board Statement: Not applicable.

Informed Consent Statement: Not applicable.

Data Availability Statement: The data presented in this study are available upon request from the corresponding author. The data are not publicly available due to privacy concerns. 
Acknowledgments: The authors would like to thank Ray Muhyi for his assistance in managing plants in the greenhouse and the field.

Conflicts of Interest: The authors declare no conflict of interest.

\section{References}

1. USDA-National Agricultural Statistics Service. Crop Values 2019 Summary. Available online: https://www.nass. usda.gov/Statistics_by_Subject/result.php?AC566EC7-7973-359F-B139-911FB30FADBF $\backslash$ T1 $\backslash$ textsectionor=CROPS\&group= VEGETABLES\&comm=ONIONS (accessed on 27 August 2020).

2. Singh, N.; Cramer, C.S. Improved tolerance for onion thrips and Iris yellow spot in onion plant introductions after two selection cycles. Horticulturae 2019, 5, 18. [CrossRef]

3. Lewis, T. Pest thrips in perspective. In Thrips as Crop Pests; Lewis, T., Ed.; CAB International: New York, NY, USA, 1997; pp. 1-13.

4. Cranshaw, W.S. Thrips. In Compendium of Onion and Garlic Diseases and Pests, 2nd ed.; Schwartz, H.F., Mohan, S.K., Eds.; APS Press: Minneapolis, MN, USA, 2008; pp. 89-91.

5. Diaz-Montano, J.; Fuchs, M.; Nault, B.A.; Shelton, A.M. Evaluation of onion cultivars for resistance to onion thrips (Thysanoptera: Thripidae) and Iris yellow spot virus. J. Econ. Èntomol. 2010, 103, 925-937. [CrossRef] [PubMed]

6. Fournier, F.; Boivin, G.; Stewart, R.K. Effect of Thrips tabaci (Thysanoptera: Thripidae) on yellow onion yields and economic thresholds for its management. J. Econ. Èntomol. 1995, 88, 1401-1407. [CrossRef]

7. Leach, A.; Fuchs, M.; Harding, R.; Nault, B.A. Iris yellow spot virus prolongs the adult lifespan of its primary vector, onion thrips (Thrips tabaci) (Thysanoptera: Thripidae). J. Insect Sci. 2019, 19, 8. [CrossRef] [PubMed]

8. Cramer, C.S.; Singh, N.; Kamal, N.; Pappu, H.R. Screening onion plant introduction accessions for tolerance to onion thrips and Iris yellow spot. HortScience 2014, 49, 1253-1261. [CrossRef]

9. Shelton, A.M.; Nault, B.A.; Plate, J.; Zhao, J.Z. Regional and temporal variation in susceptibility to lambda-cyhalothrin in onion thrips, Thrips tabaci (Thysanoptera: Thripidae), in onion fields New York. J. Econ. Entomol. 2003, 96, 1843-1848. [CrossRef] [PubMed]

10. Shelton, A.M.; Zhao, J.Z.; Nault, B.A.; Plate, J.; Musser, F.R.; Larentzaki, E. Patterns of insecticide resistance in onion thrips (Thysanoptera: Thripidae) in onion fields in New York. J. Econ. Entomol. 2006, 99, 1798-1804. [CrossRef]

11. Allen, J.K.M.; Scott-Dupree, C.D.; Tolman, J.H.; Harris, C.R. Resistance of Thrips tabaci to pyrethroid and organophosphate insecticides in Ontario. Can. Pest Mgmt. Sci. 2005, 61, 809-815. [CrossRef] [PubMed]

12. Mau, R.F.L.; Kessing, J.L.M. Thrips tabaci (Linderman). Crop Knowl. Master 1991. Available online: http://www.extento.hawaii. edu/kbase/crop/Type/t_tabaci.htm (accessed on 5 February 2019).

13. Allen, S.L.; Gillett-Kaufman, J.L. Attraction of thrips (Thysanoptera) to colored sticky traps in a Florida Olive Grove. Fla. Entomol. 2018, 101, 61-68. [CrossRef]

14. Damon, S.J.; Groves, R.L.; Havey, M.J. Variation for epicuticular waxes on onion foliage and impacts on numbers of onion thrips. J. Am. Soc. Hortic. Sci. 2014, 139, 495-501. [CrossRef]

15. Diaz-Montano, J.; Fail, J.; Deutschlander, M.; Nault, B.A.; Shelton, A.M. Characterization of resistance, evaluation of the attractiveness of plant odors, and effect of leaf color on different onion cultivars to onion thrips (Thysanoptera: Thripidae). J. Econ. Èntomol. 2012, 105, 632-641. [CrossRef] [PubMed]

16. Molenaar, N.D. Genetics, thrips (Thrips tabaci L.) resistance and epicuticular wax characteristics of nonglossy and glossy onions (Allium cepa L.). Diss. Abstr. Int. B Sci. Eng. 1984, 45, 224.

17. Alimousavi, S.A.; Hassandokht, M.R.; Moharramipour, S. Evaluation of Iranian onion germplasms for resistance to thrips. Int. J. Agric. Biol. 2007, 9, 897-900.

18. Boateng, C.O.; Schwartz, H.F.; Havey, M.J.; Otto, K. Evaluation of onion germplasm for resistance to Iris yellow spot (Iris yellow spot virus) and onion thrips, Thrips tabaci. Southwest. Èntomol. 2014, 39, 237-260. [CrossRef]

19. Gent, D.H.; Du Toit, L.J.; Fichtner, S.F.; Mohan, S.K.; Pappu, H.R.; Schwartz, H.F. Iris yellow spot virus: An emerging threat to onion bulb and seed production. Plant Dis. 2006, 90, 1468-1480. [CrossRef]

20. Cramer, C.; Mandal, S.; Sharma, S.; Nourbakhsh, S.; Goldman, I.; Guzman, I. Recent advances in onion genetic improvement. Agronomy 2021, 11, 482. [CrossRef]

21. Jones, H.A.; Clarke, A.E.; Stevenson, F.J. Studies in the genetics of the onion (Allium cepa L.). Proc. Amer. Soc. Hort. Sci. 1944, 44 , $479-484$.

22. Munaiz, E.D.; Havey, M.J. Genetic analyses of epicuticular waxes associated with the glossy foliage of 'White Persian' onion. J. Am. Soc. Hortic. Sci. 2020, 145, 67-72. [CrossRef]

23. Munaiz, E.D.; Townsend, P.A.; Havey, M.J. Reflectance spectroscopy for non-destructive measurement and genetic analysis of amounts and types of epicuticular waxes on onion leaves. Molecules 2020, 25, 3454. [CrossRef]

24. Damon, S.J.; Havey, M.J. Quantitative trait loci controlling amounts and types of epicuticular waxes in onion. J. Am. Soc. Hortic. Sci. 2014, 139, 597-602. [CrossRef]

25. Alfano, B.; Barretta, L.; Del Giudice, A.; De Vito, S.; Di Francia, G.; Esposito, E.; Formisano, F.; Massera, E.; Miglietta, M.L.; Polichetti, T. A review of low-cost particulate matter sensors from the developers' perspectives. Sensors 2020, 20, 6819. [CrossRef] [PubMed]

26. Jones, H.A.; Bailey, S.F.; Emsweller, S.L. Thrips resistance in the onion. Hilgardia 1934, 8, 213-232. [CrossRef] 
27. Greenway, G.; Kamal, N.; Nourbakhsh, S.S.; Cramer, C.S. Estimating potential changes in costs and returns from use of a partially onion thrips-resistant onion cultivar and action-based spray thresholds in Idaho and eastern Oregon. Southwest. Èntomol. 2021, 46, 349-356. [CrossRef]

28. Multani, P.S.; Cramer, C.S.; Steiner, R.L.; Creamer, R. Screening winter-sown onion entries for Iris yellow spot virus tolerance. HortScience 2009, 44, 627-632. [CrossRef]

29. Mohseni-Moghadam, M.; Cramer, C.S.; Steiner, R.L.; Creamer, R. Evaluating winter-sown onion Entries for Iris yellow spot virus susceptibility. HortScience 2011, 46, 1224-1229. [CrossRef]

30. Cramer, C.S.; Mohseni-Moghadam, M.; Creamer, R.J.; Steiner, R.L. Screening winter-sown entries for Iris yellow spot disease susceptibility. HortScience 2009, 44, 1224-1229.

31. Cramer, C.S.; Kamal, N.; Singh, N. Evaluating Iris yellow spot disease incidence and severity in onion germplasm of varying leaf characteristics. HortScience 2017, 52, 527-532. [CrossRef]

32. Kamal, N.; Nourbakhsh, S.; Cramer, C. Reduced Iris yellow spot symptoms through selection within onion breeding lines. Horticulturae 2021, 7, 12. [CrossRef]

33. Njau, G.M.; Nyomora, A.M.S.; Dinssa, F.F.; Chang, J.-C.; Malini, P.; Subramanian, S.; Srinivasan, R. Evaluation of onion (Allium сера) germplasm entries for resistance to onion thrips, Thrips tabaci (Lindeman) in Tanzania. Int. J. Trop. Insect Sci. 2017, 37, 98-113. [CrossRef]

34. Ferreira, G.D.O.; Santos, C.A.F.; Oliveira, V.R.; De Alencar, J.A.; Da Silva, D.O.M. Evaluation of onion accessions for resistance to thrips in Brazilian semi-arid regions. J. Hortic. Sci. Biotechnol. 2017, 92, 550-558. [CrossRef]

35. Raut, A.; Pal, S.; Wahengbam, J.; Banu, A.N. Population dynamics of onion thrips (Thrips tabaci lindeman, Thysanoptera; Thripidae) and varietal response of onion cultivars against onion thrips. J. Èntomol. Res. 2020, 44, 547-554. [CrossRef]

36. Singh, N.; Cramer, C.S. Selection progress for reduced Iris yellow spot symptom expression in onion. HortScience 2013, 48 , S364.

37. Cramer, C.S.; Kamal, N. Measuring selection progress in onion germplasm after one selection cycle for reduced Iris yellow spot symptom expression. HortScience 2013, 48, S363.

38. Reitz, S.R.; Cramer, C.S.; Shock, C.C.; Feibert, E.B.G.; Rivera, A.; Saunders, L.D. 2016 Evaluation of New Onion Lines for Resistance to Onion Thrips and Iris yellow Spot Virus; Malheur Experiment Station Annual Report 2015; Oregon State University Agricultural Experiment Station Ext/CrS 156; Oregon State University: Corvallis, OR, USA, 2015; pp. 170-174.

39. Kamal, N. Selection Progress and Cost Benefit Analysis of Iris Yellow Spot Resistance in Onions. Ph.D. Dissertation, New Mexico State University, Las Cruces, NM, USA, 2016.

40. Liaqat, A.; Waqar Hassan, M.; Jamil, M.; Iqbal, J.; Yaqoob, M.; Akram, M.; Ahmed, I.; Hussain, A. Effect of nursery bulb size and planting density on thrips population, plant height and yield of onion ('Phulkara' Variety) in Bahawalpur, Pakistan. Pak. J. Life Soc. Sci. 2016, 14, 96-193.

41. Walker, S.J. Bulb Onion Culture and Management for Southern New Mexico; New Mexico State University: Las Cruces, NM, USA, 2009; pp. 1-16.

42. USDA Web Soil Survey. 2021. Available online: https://websoilsurvey.sc.egov.usda.gov/App/WebSoilSurvey.aspx/ (accessed on 21 January 2022).

43. Gill, H.K.; Garg, H.; Gill, A.K.; Gillett-Kaufman, J.L.; Nault, B.A. Onion thrips (Thysanoptera: Thripidae) biology, ecology, and management in onion production systems. J. Integr. Pest Manag. 2015, 6, 6. [CrossRef]

44. Shock, C.C.; Feibert, E.B.; Riviera, A.; Saunders, L.D. Response of onion yield, grade, and financial return to plant population and irrigation system. HortScience 2015, 50, 1312-1318. [CrossRef]

45. National Onion Association. 2021. Available online: https://www.onions-usa.org/chefs-educators/foodservice/cuttingpreparation-tips-and-more (accessed on 21 January 2022).

46. Nault, B.A.; Shelton, A.M. Impact of insecticide efficacy on developing action thresholds for pest management: A case study of onion thrips (Thysanoptera: Thripidae) on Onion. J. Econ. Ėntomol. 2010, 103, 1315-1326, Erratum in J. Econ. Entomol. $2010,103$. [CrossRef] 